\section{Case Reports in Ophthalmology}

Case Rep Ophthalmol 2016;7:340-344

This article is licensed under the Creative Commons Attribution-NonCommercial 4.0 International License (CC BY-NC) (http://www.karger.com/Services/OpenAccessLicense). Usage and distribution for commercial purposes requires written permission.

\title{
Bilateral Simultaneous Rhegmatogenous Retinal Detachment following Laser in situ Keratomileusis
}

\author{
Erhan Yumusak Kemal Ornek Fatma Ozkal \\ Department of Ophthalmology, School of Medicine, Kırıkkale University, Kırıkkale, Turkey
}

\section{Keywords}

Retinal detachment · Excimer laser · Myopia

\begin{abstract}
A 21-year-old woman developed simultaneous rhegmatogenous retinal detachment after laser in situ keratomileusis (LASIK) in both eyes. She underwent pars plana vitrectomy surgery combined with endolaser photocoagulation and silicone oil tamponade in the right eye. A week later, pneumatic retinopexy was done in the left eye. As the retinal tear did not seal, $360^{\circ}$ scleral buckling surgery was performed and retina was attached. Bilateral simultaneous rhegmatogenous retinal detachment after LASIK for correction of myopia can be a serious complication. Patients should be informed about the possibility of this complication.
\end{abstract}

(C) 2016 The Author(s)

Published by S. Karger AG, Basel

\section{Introduction}

Rhegmatogenous retinal detachment (RD) is caused by liquefied vitreous passing through a retinal break into the subretinal space, separating the neurosensory retina from the retinal pigment epithelium [1]. One of the factors strongly associated with rhegmatogenous RD is myopia [1-4]. Low myopes [ -0.75 to -2.75 diopters (dpt)] show an odds ratio of 
3.14 for RD, and the odds ratio was shown to rise steeply with increasing myopic refractive errors in the population [3].

Refractive surgeries, like laser in situ keratomileusis (LASIK) and laser-assisted subepithelial keratomileusis, have been popularized for correction of low to moderate myopia [5].

Vision-threatening posterior segment complications may occur after refractive surgeries, including macular hemorrhages, macular holes and rhegmatogenous RD [6-12]. The reported incidence of rhegmatogenous RD in LASIK patients is not high, ranging from 0.033 to $0.25 \%[9,13-15]$. However, many have regarded a suction ring application during LASIK to be a potential risk factor for rhegmatogenous $\mathrm{RD}$, because this procedure may induce vitreous traction and detachment resulting from sudden decompression of the eye [16,17]. It has been reported that retinal breaks were more commonly located in the inferotemporal quadrant in rhegmatogenous RD after LASIK [18].

Here, we report on a case with bilateral simultaneous rhegmatogenous RD following LASIK surgery.

\section{Case Presentation}

A 21-year-old female had bilateral LASIK surgery 18 months ago. She was admitted to us for decreased vision in the right eye. She was wearing a correction for myopia with a prescription of $6.5 \mathrm{dpt}$ in the right eye and $7.00 \mathrm{dpt}$ in the left eye. Her past medical history was unremarkable.

On initial examination, visual acuity was counting fingers at $1 \mathrm{~m}$ on the right and 10/10 on the left. She had LASIK flap scar with minimal haze on both corneas. Dilated fundus examination revealed a total RD secondary to a retinal tear at approximately 11 o'clock in the right eye. There was a localized RD secondary to retinal tear at approximately 13 o'clock in the left eye, and the posterior pole was attached (fig. 1a-d).

The patient underwent pars plana vitrectomy surgery combined with endolaser photocoagulation and silicone oil tamponade in the right eye. A week later, pneumatic retinopexy was done in the left eye. As the retinal tear did not seal, a $360^{\circ}$ scleral buckling surgery was performed and the retina was attached. On the last visit, visual acuity was $4 / 10$ in the right eye and 10/10 in the left eye. There was a mild posterior subcapsular cataract in the vitrectomized eye. Four months later, the retina was firmly attached on both sides.

\section{Discussion}

High myopia is one of the causative factors in rhegmatogenous RD [19]. Risk of RD is 10fold higher in eyes over $3.0 \mathrm{dpt}$ and is $0.075 \%$ in eyes exceeding $10 \mathrm{dpt}$ [20]. There are several reports on post-LASIK RD and most of these cases have high myopia (>10 dpt) [21, 22]. Increased vitreous liquefaction, earlier posterior vitreous detachment and higher incidence of vitreoretinal degeneration, such as lattice degeneration, are thought to be attributable to the higher prevalence in rhegmatogenous RD in myopes [1]. In our case, there was bilateral rhegmatogenous RD in both eyes at the same time. As far as we know, no such case has been reported previously.

Ozdamar et al. [7] reported a bilateral RD with giant retinal tear following LASIK surgery. There was a 6-month interval between the two eyes. Reviglio et al. [23] presented a case with high myopia $(-13.00+3.00 \times 15 \mathrm{dpt}$ in the right eye and $-13.00+3.00 \times 170 \mathrm{dpt}$ in 
Case Reports in
Ophthalmology

Case Rep Ophthalmol 2016;7:340-344

\begin{tabular}{l|l}
\hline $10.1159 / 000446602$ & ( 2016 The Author(s). Published by S. Karger AG, Basel \\
\hline
\end{tabular} www.karger.com/cop

Yumusak et al:: Bilateral Simultaneous Rhegmatogenous Retinal Detachment following Laser in situ Keratomileusis

the left eye) who developed RD $14 \mathrm{~h}$ after LASIK surgery. Arevalo et al. [18] evaluated 1,1594 LASIK patients with myopia in a 10-year follow-up. They found RD in 22 eyes of 19 patients during the course (ranging between 1 month and 10 years). Eighteen RD cases were diagnosed in the first 12 months (81\%).

Myopic eyes carry the potential for retinal tears and RD [24]. Therefore, LASIK surgery could not be the only causative factor for RD in these eyes. Long axial length, vitreous changes and peripheral retinal abnormalities are major risk factors [25]. There is a positive correlation between RD and the amount of myopia. In a study by Ogawa and Tanaka [3], patients with $>15$ dpt myopia exhibited a high frequency of RD. Qin et al. [14] reported 6 RD cases in 9,598 LASIK patients $(0.033 \%)$. The mean duration of RD development was 9.25 months. Another study reported 10 RD cases in 12,760 LASIK surgeries [26].

As known, myopia increases the risk of RD (from 0.70 to 6\%) [27]. This amount is higher than for post-LASIK RD cases. The difference may be due to detailed fundus examination and preventive interventions prior to LASIK surgery. The time course between LASIK surgery and RD was 18 months in our case. It was in accordance with two previous large series which reported 16.3 and 27.3 months, respectively [22, 27].

All the previously reported cases in the literature were either unilateral RD or bilateral RD presenting at separate times following LASIK. Simultaneous RD patients, as a subgroup of bilateral RD, may have more severe retinal weakness. Younger patients with myopia and coexisting retinal degenerations may be predisposed to simultaneous RD as in this case.

To conclude, although LASIK surgery is still an effective and safe method used to correct myopia, bilateral simultaneous RD should be included in the postoperative LASIK complications. A thorough and careful retinal examination should be done before surgery, particularly in young myopic patients.

\section{Statement of Ethics}

The authors have no ethical conflicts to disclose.

\section{Disclosure Statement}

The authors have no proprietary interests in the materials described in the paper.

\section{References}

1 Ghazi NG, Green WR: Pathology and pathogenesis of retinal detachment. Eye 2002;16:411-421.

-2 Mitry D, Charteris DG, Fleck BW, Campbell H, Singh J: The epidemiology of rhegmatogenous retinal detachment: geographical variation and clinical associations. Br J Ophthalmol 2010;94:678-684.

-3 Ogawa A, Tanaka M: The relationship between refractive errors and retinal detachment: analysis of 1,166 retinal detachment cases. Jpn J Ophthalmol 1988;32:310-315.

4 The Eye Disease Case-Control Study Group: Risk factors for idiopathic rhegmatogenous retinal detachment. Am J Epidemiol 1993;137:749-757.

-5 Zaldivar R, Davidorf JM, Oscherow S: Laser in situ keratomileusis for myopia from -5.50 to -11.50 diopters with astigmatism. J Refract Surg 1998;14:19-25.

6 Arevalo JF: Posterior segment complications after laser assisted in situ keratomileusis. Curr Opin Ophthalmol 2008;19:177-184.

7 Ozdamar A, Aras C, Sener B, Oncel M, Karacorlu M: Bilateral retinal detachment associated with giant retinal tear after laser-assisted in situ keratomileusis. Retina 1998;18:176-177. 
8 Ruiz-Moreno JM, Perez-Santoja JJ, Alio JL: Retinal detachment in myopic eyes after laser in situ keratomileusis. Am J Ophthalmol 1999;128:588-594.

-9 Arevalo JF, Ramirez E, Suarez E, et al: Rhegmatogenous retinal detachment after laser-assisted in situ keratomileusis (LASIK) for the correction of myopia. Retina 2000;20:338-341.

10 Charteris DG: Retinal detachment associated with excimer laser. Curr Opin Ophthalmol 1999;10:173176.

-11 Luna JD, Reviglio VE, Juarez CP: Bilateral macular hemorrhage after laser in situ keratomileusis. Graefes Arch Clin Exp Ophthalmol 1999;237:611-613.

-12 Arevalo JF, Mendoza AJ, Velez-Vazquez W, et al: Full-thickness macular hole after LASIK for the correction of myopia. Ophthalmology 2005;112:1207-1212.

13 Arevalo JF, Ramirez E, Suarez E, et al: Incidence of vitreoretinal pathologic conditions 24 months after laser-assisted in situ keratomileusis (LASIK). Ophthalmology 2000;107:258-262.

14 Qin B, Huang L, Zeng J, Hu J: Retinal detachment after laser in situ keratomileusis in myopic eyes. Am J Ophthalmol 2007;144:921-923.

15 Aras C, Ozdamar A, Karacorlu M, et al: Retinal detachment following laser in situ keratomileusis. Ophthalmic Surg Lasers 2000;31:121-125.

16 Arevalo JF, Ramirez E, Suarez E, et al: Rhegmatogenous retinal detachment in myopic eyes after laser in situ keratomileusis: frequency, characteristics, and mechanism. J Cataract Refract Surg 2001;27:674680.

17 Flaxel CJ, Choi YH, Sheety M, Oeinck SC, Lee JY, McDonnell PJ: Proposed mechanism for retinal tears after LASIK: an experimental model. Ophthalmology 2004;111:24-27.

18 Arevalo JF, Lasave AF, Torres F, Suarez E: Rhegmatogenous retinal detachment after LASIK for myopia of up to -10 diopters: 10 years of follow-up. Graefes Arch Clin Exp Ophthalmol 2012;250:963-970.

19 Curtin BJ: The Myopias: Basic Science and Clinical Management. Philadelphia, Harper \& Row, 1985, pp 337-339

20 Michels RG, Wilkinson CP, Rice TA: Retinal Detachment. St. Louis, Mosby, 1990, pp 83-84.

-21 Arevalo JF, Ramirez E, Suarez E, et al: Rhegmatogenous retinal detachment in myopic eyes after laser in situ keratomileusis; frequency, characteristics, and mechanism. J Cataract Refract Surg 2001;27:674680.

-22 Arevalo JF, Ramirez E, Suarez E, et al: Retinal detachment in myopic eyes after laser in situ keratomileusis. J Refract Surg 2002;18:708-714.

23 Reviglio VE, Kuo IC, Gramajo L, Olmedo MA, Falco M, Juarez CP: Acute rhegmatogenous retinal detachment immediately following laser in situ keratomileusis. J Cataract Refract Surg 2007;33:536539.

24 Curtin BJ: The Myopias: Basic Science and Clinical Management. Hagerstown, Harper \& Row, 1985, p 334 .

25 Wilkinson CP, Rice TA: Michels Retinal Detachment. St. Louis, CV Mosby, 1997, p 77.

26 Lee SY, Ong SG, Yeo KT, Wong DW, Ang CL: Retinal detachment after laser refractive surgery at the Singapore National Eye Centre. J Cataract Refract Surg 2006;32:536-538.

-27 Faghihi H, Jalali KH, Amini A, et al: Rhegmatogenous retinal detachment after LASIK for myopia. J Refract Surg 2006;22:448-452. 


\section{Case Reports in Ophthalmology}

\begin{tabular}{l|l}
\hline Case Rep Ophthalmol 2016;7:340-344 \\
\hline $10.1159 / 000446602$ & $\begin{array}{l}\text { ○ 2016 The Author(s). Published by S. Karger AG, Basel } \\
\text { www.karger.com/cop }\end{array}$ \\
\hline
\end{tabular}

Yumusak et al.: Bilateral Simultaneous Rhegmatogenous Retinal Detachment following Laser in situ Keratomileusis
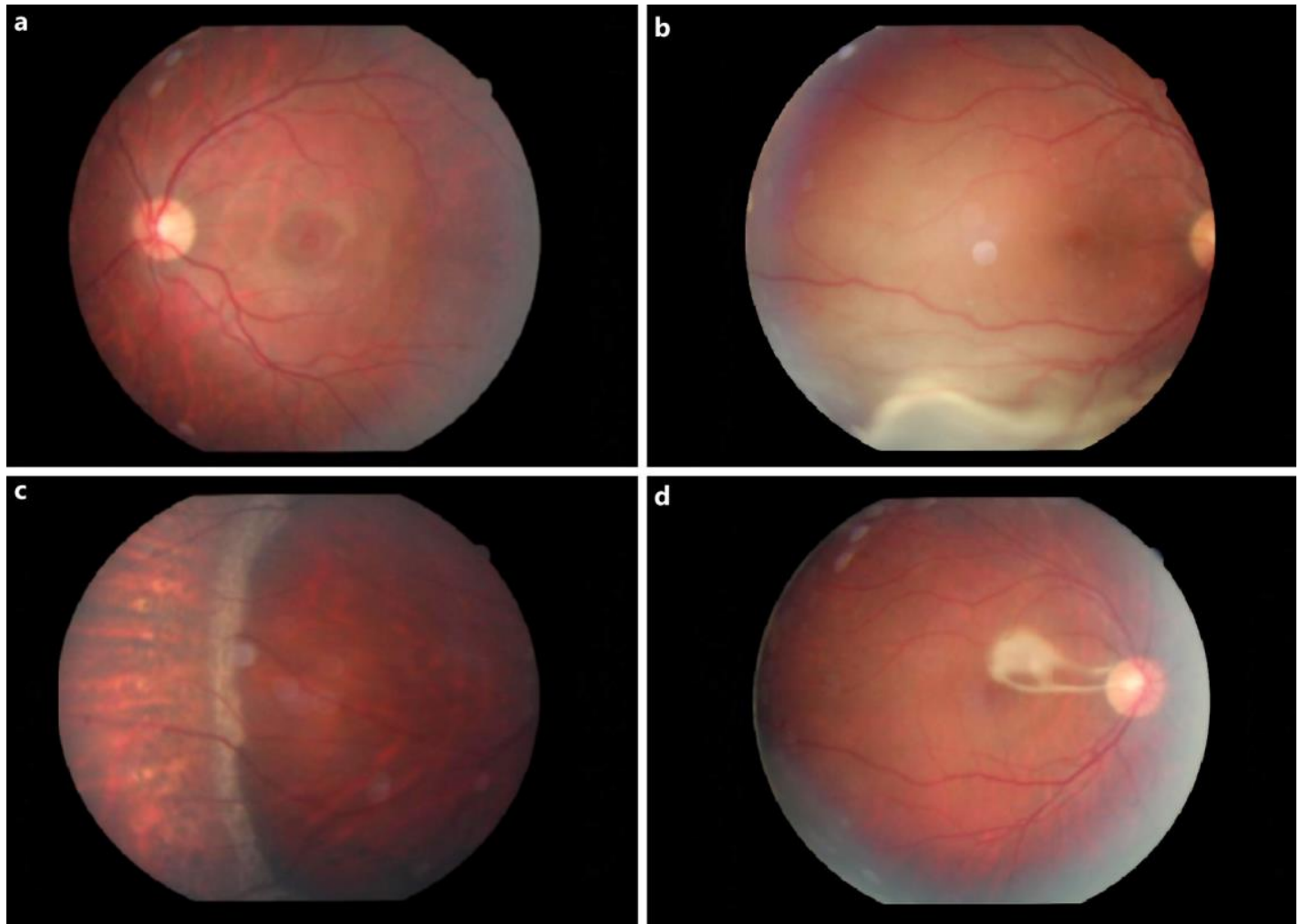

Fig. 1. $\mathbf{b}$ Total RD in the right eye. a Attached posterior retina in the left eye. $\mathbf{d}$ Retina filled with silicone is attached after surgery in the right eye. c Attached retina with scleral buckling in the left eye. 